"Prominent challenges of fixed-term contracts for administrative and professional employees in higher learning institutions of Gauteng Province, South Africa"

$\begin{array}{ll}\text { AUTHORS } & \text { Elsie Skeni Monkwe } \\ \text { Solly Matshonisa Seeletse }\end{array}$

Elsie Skeni Monkwe and Solly Matshonisa Seeletse (2016). Prominent challenges of fixed-term contracts for administrative and professional employees

ARTICLE INFO in higher learning institutions of Gauteng Province, South Africa. Problems and

Perspectives in Management, 14(3-3), 650-656. doi:10.21511/ppm.14(3-

3).2016.08

DOI

http://dx.doi.org/10.21511/ppm.14(3-3).2016.08

RELEASED ON

Thursday, 10 November 2016

JOURNAL

"Problems and Perspectives in Management"

FOUNDER

LLC "Consulting Publishing Company "Business Perspectives"

NUMBER OF REFERENCES

0

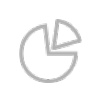

NUMBER OF FIGURES

0

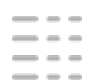

NUMBER OF TABLES

0

(C) The author(s) 2022. This publication is an open access article. 
Elsie Skeni Monkwe (South Africa), Solly Matshonisa Seeletse (South Africa)

\title{
Prominent challenges of fixed-term contracts for administrative and professional employees in higher learning institutions of Gauteng Province, South Africa
}

\begin{abstract}
The use of temporary workers by organizations is growing, and has extensively extended to higher learning institutions (HLIs). This paper discusses the challenges of fixed term contract administrative and professional employees (FTC A/Ps) in Gauteng Provinces' HLIs in South Africa. The research methodology used was exploratory. Surveys were used to collect data. The study sample consisted of 107 FTC A/Ps. Primary data were collected using a questionnaire. Text data were analyzed using the thematic content analysis of qualitative design. The study revealed that the HLIs did not provide training to the FTC A/Ps, but required them to perform as if they were trained. The FTC A/Ps were not getting employee benefits, were abused, underpaid, lacked privileges, lacked morale, could be dismissed any time, were driven to lose trust on managers and to be disloyal to their HLIs. They sometimes caused unscheduled turnover. Their commitment to work diminished. Still, they were bound to increase their productivity under punitive working conditions. The study recommends involving of FTC A/Ps when necessary, and not to abuse them. This also includes possibilities of integrating them in the HLI workforce, but to put proper precautionary measures when empowering them.
\end{abstract}

Keywords: abuse, fixed term contract, higher learning institutions, roll over.

JEL Classification: J71, J81, J82.

\section{Introduction}

The topic of contract and casual workers is relatively unexplored in South African academic research, even though at trade union level it has been a prickly issue for some time. There are still organizations in the country that employ people for core activities on casual and contract bases. However, legislation has discouraged this practice where permanent fulltime appointment is justifiable (South Africa, 1999). According to Venter (2003), changes have been experienced occasionally since 1994 when the Labor Relations Act (LRA) was introduced in South Africa. Also, employers seem to apply the LRA differently and, in some cases, abusively. Many employees who are employed on fixed-term contracts (FTCs) accept this offer because of lack of permanent or alternative employment. Everyone seeking employment generally wants a permanent job with full benefits. The FTC employees usually do not have full benefits, but are required to perform at the same level as employees who receive full benefits. There is, however, plentiful evidence that workplaces can be sustained, improved and made more beneficial for communities, employees and other stakeholders if everyone contributing to the work is employed on a PE and rewarded appropriately (Saurin, 2012). This paper focuses on the challenges faced by employees of FTCs in some HLIs of the Gauteng Province, South Africa. Conley and Steward (2008) point that higher education (HE) has been particularly affected by the growth of FTC

(C) Elsie Skeni Monkwe, Solly Matshonisa Seeletse, 2016.

Elsie Skeni Monkwe, Directorate of Research, Sefako Makgatho Health Sciences University, Gauteng Province, South Africa.

Solly Matshonisa Seeletse, Department of Statistics \& Operations Research, Sefako Makgatho Health Sciences University, Gauteng Province, South Africa. employment. The core business of academic institutions is academia with academics being core staff, but support personnel play a crucial role in the HLIs. The support employees of HLIs, consisting of administrative and professional employees on FTCs (hereinafter referred to as FTC A/P), were the targeted study population for this study.

\section{Notion of FTC}

The term FTC refers to a contractual agreement that binds an employee to work for an employer for a specified period (Conley \& Steward, 2008). This type of employment is similar to a contract of permanent employment (PE) in terms of times of day for work and expectations on performance levels. However, it differs from PE in that employees on FTC do not get some benefits, and the terms of contact is limited in duration without consideration to retirement age. Also, the $\boldsymbol{F T C}$ stipulates a starting date and an ending date. The duration of the contract is clearly specified between employer and employee.

1.1. Conditions of service of employees on FTC. Despite the conditions stated about FTC, employees on FTCs are expected and required to perform at the level of their PE counterparts. The employers may set different working conditions for the FTC employees. There are cases where these employees may neither embark on labor strikes nor join labor unions. The initiatives of the South African government to protect the practices that discriminate employees on FTC were incorporated only in May 2015 (Laubscher \& Wilsenach, 2015). These were aimed at protecting the employees on FTC and others with similar fates. The goal of the initiative was to create jobs, as well as emphasize acceptable work quality. It was also a way 
to find options to give all employees a fair, deal and to initiate platforms for long term sustainable growth (Thompson, 2003).

1.2. Remuneration of employees on FTCs. Ideally, remuneration packages of employees on FTC should match those on PE. However, Barbieri and Culiuti (2009) state that, in most cases, employees on FTCs earn much less than those on PE. This makes them earn much lower than those on PE in many cases where they have no employee benefits. This is one reason why some employers are perceived as reaping profits at the cost of cheap labor and abuse of employment conditions.

1.3. FTC employees in organizations. Many employees on FTC would prefer to be on PE contracts. Accepting FTC occurs mainly as a compromise when employments in desired jobs do not materialize. De Graaf-Zijl (2012) states that in the United Kingdom, most companies employ on FTCs more than they do on a PE basis. Due to competition on the jobs, a FTC always serves as a perceived opportunity to impress the employers with the hope of being converted as a $\mathrm{PE}$ employee. Some happen that way, and many more others never materialize.

1.4. Reasons for FTCs. Companies may genuinely be requiring employees on a temporary basis. However, many companies use the FTC option even when PE is justifiable and, then, renew FTCs without converting them to permanent (Hepple, 2004). Some of these companies deliberately do so to abuse the loopholes of law. Other reasons may be lack of funds, to company or industry instability, and relative enterprise insolvency. Some organizations defiantly abuse the law by exploiting the workers.

1.5. The value of embarking on FTC research in HLIs. The FTC topic is a sensitive issue to employers, but useful for various reasons related to ethical labor practice. Many employees in FTCs are denied employee benefits, while performing and producing profits for their organizations (Mokoditoa, 2011). Addressing and resolving this puzzle can help to restore the payable benefits for many individuals. The paper interest in exploring FTCs may lead to improved practices in these workplaces. Another interest lies in helping to enhance sustainable growth of HLIs. This paper also has potential to serve as a useful benchmark for improved human resources practices and, therefore, enhancing economic growth in the long term.

1.6. Likely influence of this paper. The literature available on FTC is much less than the court cases involving complainants claiming that employees were treated undesirably by employers (Basson et al., 2005; Van Zyl \& Rudd, 2006). This paper makes an academic contribution to the literature. It also enhances and encourages rational human resources recruitment practices. Increased relevant literature has some potential to reduce lawsuits, as the practitioners can benefit by referring to literature for good practices. In addition, this paper can serve practices in both academia and other sectors.

\section{Human resource and FTC}

According to Wandera (2011), human resources (HR) policies are systems of classified decisions for an organization to support administrative personnel functions, performance management, employee relations and resource planning. Companies have different conditions. Hence, each one develops its policies. These policies provide a mechanism to manage risk by matching trends in employment standards and satisfying the legislation. Also, the policies are framed for the individual companies (Taylor \& Collins, 2000).

2.1. Reasons for employers to use short term workers. FTC provides the employers with control over the employee, while the employee has little or no security regarding their working situation (Thorsteinson, 2003). The FTC A/Ps have to honour normal working hours and terms of the contract, but have no access to fringe benefits. They are also not given the training which the PEs receive (Connelly \& Gallagher, 2004). This may lower the quality of work. Some companies use FTC A/Ps when rare or intermittent high work demands appear. Others use them during decreased productivity to increase productivity. Others involve them when they deal with lower demand. In general, though three reasons for employers to use short term workers are flexibility of staffing, reduction of costs and ease of dismissal (Kalleberg, Reynolds \& Marsden, 2003; Valverde, Tregaskis and Brewster, 2000). Flexibility helps companies for suppleness and adaptation to the economic changes in maintaining high profits. Another main benefit of utilizing FTC A/Ps is to reduce recruitment costs (Allan, 2002). Also, FTC A/Ps are easy to dismiss without having to incur high costs. Thus, ease of their dismissal is another employer advantage of using FTCs.

2.2. Effects of short term employment to organizations. According to McInnis, Meyer and Feldman (2009), the main effects of FTCs are unscheduled turnover, low staff morale and low levels of employee productivity.

2.2.1. Unscheduled turnover. The FTC A/P can withdraw their services early when better opportunities emerge elsewhere, or when they get too frustrated (Backhaus \& Tikoo, 2004). Such departure affects organization that would have benefited at the pre-planned withdrawal time. There is minimal investment on FTC A/Ps. Hence, most of the revenue generated from using FTC is profit. Even then, failure 
to effectively integrate FTC A/Ps into the HLIs could deepen the unscheduled turnover problem (Burgess \& Connell, 2006).

2.2.2. Low morale. FTC employees started long ago when PEs taking leave were replaced on a short term basis. Currently, these employees are being used in some organizations for core activities. According to Bourhis and Wils (2001), this can have an effect on employee, because FTCs and PEs may be working together on the same job, but under different compensation and benefits terms. In addition, FTC workers often do not get the same training, thereby affecting the risk level in some jobs.

2.2.3. Low levels of employee productivity. The nature of temporary employment increases feelings of divided allegiance on the part of temporary workers (Wiens-Tuers \& Hill, 2002). FTC is a form of underemployment. Any underemployment in terms of suboptimal skill utilization might make FTC employees less involved. Organizations allocate fewer resources to training and socializing FTC employees than to PEs.

2.3. FTC issues. The FTC A/Ps have no employee benefits, and are vulnerable. They probably suffer due to lack of income, and take FTC as a compromise employment option. Their contracts may even be extended with unfavorable conditions that neither compromise not commit the organization to empowering them. Also, in many cases, these may be violating the applicable legislation (Venter, 2003).

2.3.1. Employee benefits for FTC A/Ps. Many employers do not give employee benefits to FTC employees. However, there are some employers who give standard benefits, or some of these benefits. In the FTC, the employer states the benefits such as bonus (or $13^{\text {th }}$ cheque), pension, medical aid, provident fund, group life assurance facility, and so on, as may be applicable (van Wyk, van Heerden \& Feldman, 2015). Regrettably, some employers use the FTCs to save money by denying employees the opportunities of pension and provident fund benefits and medical aid benefits. Moreover, if an employee on FTC is retrenched, he or she can be denied their severance pay.

2.3.2. Rolling over of FTC. According to several authors (Foote \& Folta, 2002; Foote, 2004; Voudouris, 2004), some employers continue to renew FTCs every time they expire. This is known as "rolling over" the contract. In South Africa, according to Zijl, van den Berg and Heyma (2004), rolling over of FTCs is not forbidden for an employer. Once, or at the most twice rolling over of FTCs is acceptable. However, if a contract has been rolled over for the third or fourth time, the employee would have 'the right of expectation'. This means that the employee has the right to expect that such a situation will continue, and their contract will be renewed. If it is not, and the employee is dismissed, there are strong grounds to take the employer to the Commission for Conciliation, Mediation and Arbitration (CCMA) on the grounds of unfair dismissal.

2.3.3. Affirmative action. In South Africa, affirmative action (AA) is the employment policy of supporting members of disadvantaged groups who historically have suffered from discrimination in job sectors, such as blacks during apartheid, women and the people with disabilities (Edigheji, 2007). Hasmath (2011) informs that in Canada, AA is known as employment equity, in the UK it is positive discrimination and it is reservation in both India and Nepal. Though heavily abused in countries that lack monitoring mechanisms, it is intended to balance the impacts of past imbalances by accelerating empower the previously disadvantaged population groups.

\section{Methodology}

3.1. Study scenery. An exploratory study is a comprehensive, thorough investigation of a number of cases and their related contextual conditions (Yin, 2014). In this study, the cases of focus consist of eight HLIs in the Gauteng Province of South Africa. The study interest was mainly on administrative and professional employees who were on FTCs. The intent of the study was to analyze the conditions of these employees, decisions that could have led to FTC employment, periods of their employment, the policies used to employ them, and any aspect of relevance to the FTC issue at these HLIs. Thomas (2011) supports this research approach. He considers the approach as a platform to inform and clarify the study concerns. The data collection was undertaken through emailed research questions that included open requests to enable open sharing of their experiences (Baškarada, 2014). The respondents were given time and space to respond at their leisure.

3.2. Research design. The study was qualitative in design in order to generate possible leads and ideas. According to Hennink, Hutter and Bailey (2011), qualitative research entails studies whose purpose is to gather data or facts in instances where little is known about the field of study. This is a mechanism that enabled anticipation of appropriate research decisions for maximizing the validity of the eventual results (Gravetter \& Forzano, 2010). It dealt with the data needed, data sources, data collection methods, data analyzes and data interpretation methods. The design should ensure that investigations strive for quality and excellence, justify the efforts and make a contribution in an aspect of life (Marshall \& Rossman, 2010). Hence, the empirical study used two research methods in order to gather plentiful relevant information. These 
methods were emailed questionnaire using a selfdesigned piloted and validated questionnaire, and document review. The study consisted of soliciting responses from HLI FTC A/Ps.

3.3. Population and sample. The study population consisted of FTC A/Ps in Gauteng Provinces' HLIs. The estimated population size provided by HR officials gave about 214 FTC A/Ps. Newly merged HLIs were having more members as compared to the undisturbed ones. The study targeted a sampling ratio of $30 \%$, thus, requiring 65 respondents. In anticipation of nonresponses, a 50\% sampling ratio was used for questionnaire distribution to increase responses. These were 107 FTC A/Ps who all responded. Approximate proportional sample sizes were used in the HLIs, and the emails were distributed to the simple random samples selected members on each campus. Since collective issues were of importance, instead of comparison, there were no attempts to associate issues with the various campuses. Further, consistencies of treatment seemed to prevail.

3.4. Data collection. The study collected primary data by self-administered questionnaires to FTC $\mathrm{A} / \mathrm{Ps}$ in the campuses involved. An open-ended questionnaire asking for the respondents' first-hand experiences was used, with questions relating to their conditions as FTC employees in HLIs. The main reason for going through this process was to obtain their opinions and acquire more inputs to understand their conditions and experiences. The questionnaires were emailed to the respondents.

3.5. Considerations. The study considered issues of anonymity, confidentiality and informed consent (Creswell, 2014). No respondents names were required. The information on the various documents from HR was given on the condition that the names of the HLIs would remain undisclosed. Information distributed was aggregated, and not allocated to specific respondents. Furthermore, a letter was drafted to introduce and explain the study aspirations.

3.6. Documentary review. The documents perused as part of data collection to source information were the manuals for FTC and other employees in the campuses. Some were requested from the HR offices, while others were available on websites of the institutions. This process took a period of about five months to scrutinise the documents.

3.7. Data analysis method. Thematic analysis approach was applied on the documents perused, and from the returned questionnaires. The method aspires to identify and describe the central ideas (usually referred to as themes or categories) occurring in data (Braun \& Clarke, 2013). It basically attempts to identify themes from the study responses.

\section{Results and discussions}

Themes were created from the respondents' deliberations. The ubiquitous ones were abuse by the full time counterparts, abuse by PEs, abuse by academics (including those who are also on contract), bonus deprivation, deflated appraisal, displaced appraisal, benefits deprivation by employer, lack of support from employers, being trapped into erring, jealous by PEs who wished FTC for their friends/relatives, and undue instructions from permanent employees. One disturbing trap was the FTC A/Ps being made messengers even when they are busy with a task. Therefore, being blamed for not performing on the task from which they were shifted. According to them, refusals to act as messengers were appraised as insubordination. The main problem was lack of policies for reporting and complaint, as well as a lack of clear procedures. This made the FTC A/Ps vulnerable, as they needed to perform to warrant permanent appointments.

Some other shocking findings were established. The study found that PEs sometimes shifted all the responsibilities to the FTC A/Ps for their own personal career development. Due to the conditions of subjugation and insecurity, FTC A/Ps were obliged to perform duties meant for the PEs. They lost trust, as well on their managers who allowed such exploitation. Meanwhile, while they usually performed those duties, they remained uncertain about their own fate.

The FTC A/Ps were not satisfied with work-care arrangements since no such arrangements existed for them. Also, the FTC conditions did not provide workhome culture. The FTC A/Ps claimed to be less committed, lacked trust, felt unfairly treated, and had lower affective attachment to employers. The job provided little or no satisfaction for them, except the consolation of some monetary reward. Despite these, FTC A/Ps claimed that they worked harder, not necessarily because they wanted to, but mostly because they were forced.

Many of the FTC A/Ps indicated that they had verified that they were earning lower salaries than their PE counterparts. They also pointed out that they did not receive the $13^{\text {th }}$ cheques, or any bonuses.

There were also cases of FTC A/Ps who were reporting to expatriates who were heading academic departments. Apparently, these FTC A/Ps were illtreated and even trapped to err. The heads of departments (HoDs) would bait them to take leave, then, a replacement would be brought in. Where mistakes occur from this substitute, the baited FTC $\mathrm{A} / \mathrm{P}$ would be credited with this error. On performance appraisals, the $\mathrm{HoD}$ completed appraisal forms and then instructs the FTC A/P to sign without reading. Also, when locals acted as FTC A/Ps, they received 
limited training and no support. They got pressure, and work was deliberately made difficult for them. Suspicions of 'constructive dismissals' also occurred. On the other hand, foreign participants were trained, supported, and appraised favorably.

Furthermore, some foreign (expatriate) male HoDs would bring their own wives to work as replacements of FTC A/P. Use of different surnames served as an advantage to cheat the system, as such nepotism was not detected. First; the husband would present the wife as a 'woman' for AA purpose. He would, then, enable the wife to be trained using HLI training funds. They would, therefore, empower the wife for jobs somewhere else.

\section{Conclusions}

The discussions show that FTC A/Ps in HLIs of Gauteng Province believed that people in authority did not take their fate seriously. Many of them were eager to be heard, hoping that their frustrations be addressed. They responded to this study eager to be heard, mainly to register and stress their frustrations in FTCs. This study benefitted from the FTC A/Ps' willingness to share their experiences.

The FTC A/Ps experienced abuses from other employees, and even from academic FTC employees. They had no employee benefits. Their experiences included jealousy from PEs who wanted their own associates to be on these contracts. They were also occasionally trapped to make mistakes. The PEs would shift all the responsibilities to the FTC A/Ps. The PEs would, then, participate on other activities such as career development. Eventually, the FTC A/Ps lost trust on their managers. They were treated badly. On their occupation fate, they remained uncertain.

Overall, the FTC A/Ps were unsatisfied with work conditions. They lost motivation, felt unfairly treated, and had lower affective attachment to employers, among others. Their remuneration was low. They got no bonuses. Despite these, FTC A/Ps worked harder, because they were compelled.

Those FTC A/Ps reporting to HoDs of foreign origin were apparently in worse conditions. In addition to the bad experienced every FTC A/P had, the ones reporting to foreign HoDs were also used for empowerment of the relatives of these HoDs. It seemed as though they received escalated abuses in general.

The study established that the FTC A/Ps could be removed with ease, and also at minimum costs. Furthermore, some HLIs reduced their recruitments costs by paying low salaries using FTC A/Ps and giving limited benefits. Lastly, there was an increasing tendency by employers to use FTC A/Ps to reduce labor costs. This was a strong indication that the FTC A/Ps were abused.

\section{Discussion}

The fate of FTC A/Ps seemed to depend on the managers' discretions. The PEs also seemed to have had some influence in the fate of the FTC A/Ps. Many FTC A/Ps seemed to work under punitive conditions. Their abuses seemed to be rife in many of these HLIs.

Some of the FTC A/Ps had to satisfy both the managers and the PEs. These PEs included the levels at which the FTC A/Ps were appointed, and some at lower levels.

There was no investment from the HLIs to empower or uplift the FTC A/Ps, but they required performance and productivity from them. The experiences that the FTC A/Ps acquired from these temporary contract opportunities were based primarily on the employees' own initiatives of knowing and learning to work.

Furthermore, the FTC A/Ps knew that in these short-term work arrangements, they could be replaced with ease and even with immediate effect if they resisted or questioned any management decision about their plight.

Lastly, the HLIs could remove the FTC A/Ps cheaply. The FTC A/Ps assisted in reducing recruitment and labor costs for HLIs.

\section{Recommendations}

The study recommends that HLIs should employ FTC A/Ps during economic difficulties only when it is the only option left. They should also inform the FTC $\mathrm{A} / \mathrm{Ps}$, give them training, and also prioritize them when the HLI recovers to be able to appoint them.

The study also recommends that the HLIs should implement proper human asset management practices to reduce high rates of unscheduled turnover. When opportunities arise, the HLIs should integrate FTC A/Ps into their workforce.

The study further recommends that the HLIs should offer induction and investment in skills development of FTC A/Ps by training them to increase productivity and increase their motivation. This could enhance the FTC A/Ps commitment to work.

In order to curtail abuses of the FTC A/Ps, the FTC A/Ps should be organized. It is recommended that the FTC A/Ps should be represented by employee unions. They should be included in the collective bargaining process and agreements.

Lastly, the HLIs should design policies to protect and effectually reward FTC A/Ps that also have effective monitoring and preventive systems. 


\section{References}

1. Allan, P. (2002). The short time workforce: challenges and new directions, American Business Review, June, pp. 103-110.

2. Backhaus, K. \& Tikoo, S. (2004). Conceptualizing and researching employer branding, Career Development International, 9, pp. 1-5.

3. Barbieri, P. \& Cutuli, G. (2009). Equal job, unequal pay; fixed term contracts and wage differentials in the Italian Labor Market. Working Paper, Dipartimento di Sociologia e Ricerca Sociale, Università di Trento.

4. Baškarada, S. (2014). Qualitative case study guidelines, The Qualitative Report, 19 (40), pp. 1-25.

5. Basson, A., Christianson, M., Gabers, C., Le Roux, P.A.K., Mishke, C. \& Strydom, E.M.L. (2005). Essential Labor Law. $4^{\text {th }}$ edition. Labor Law Publications, Durban, Oxford.

6. Bourhis, A. \& Wils, T. (2001). The fragmentation of traditional employment: challenges raised by the diversity of typical and atypical jobs, Industrial Relations, 56 (1), pp. 66-91.

7. Braun, V. \& Clarke, V. (2013). Successful qualitative research: A practical guide for beginners. London: Sage Publications.

8. Burgess, J. \& Connell, J. (2006). Short term work and Human Resource Management: Issues, challenges and responses, Personnel Review, 35 (2), pp. 129-140.

9. Conley, H. \& Steward, P. (2008). Representing fixed-term workers: the anatomy of a trade union Campaign, Employee Relations, 30 (5), pp. 515-533.

10. Connelly, C.E. \& Gallagher, D.G. (2004). Emerging trends in short time work research, Journal of Management, 30, pp. 959-983.

11. Creswell, J.W. (2014). Research design: Qualitative, quantitative and mixed methods approaches. $4^{\text {th }}$ edition. University of Nebraska, Lincoln: Sage Publications.

12. Edigheji, O. (2007). Affirmative action and state capacity in a democratic South Africa, Policy: Issues \& Actors, 20 (4), pp. 1-13, Centre for Policy Studies, Johannesburg, South Africa, February.

13. Foote, D.A. (2004). Short term workers: Managing the problem of unscheduled turnover. Department of Management and Marketing, Middle Tennessee State University, Murfreesboro, Tennessee, USA.

14. Foote, D.A. \& Folta, T.B. (2002). Short term employees as real options, Human Resource Management Review, 12 , pp. 579-597.

15. Gravetter, F.J. \& Forzano, L.B. (2010). Research methods for the behavioral sciences. $4^{\text {th }}$ edition. Wadsworth: Cengage Learning.

16. Grogan, J. (2005). Dismissal discrimination and unfair labor practice. Landsdowne: Juta Law.

17. De Graaf-Zijl, M. (2012). Compensation of on-call and fixed-term employment: The role of uncertainty, The Manchester School, 80 (1), pp. 6-27.

18. Hasmath, R. (2011). The education of ethnic minorities in Beijing, Ethical and Racial Studies, 34 (11), pp. 1835-1854.

19. Hennink, M., Hutter, I. \& Bailey, A. (2011). Qualitative research methods. Thousand Oakes: Sage Publications.

20. Hepple, B. (2004). Social and labor rights in a global context. Cambridge Cambridge University Press.

21. Kalleberg, A.L., Reynolds, J. \& Marsden, P.V. (2003). Externalizing employment: Flexible staffing arrangements in US organizations, Social Science Research, 32, pp. 525-552.

22. Laubscher, T. \& Wilsenach, H. (2015). Fixed term employees - stricter regulation. 12 May 2015. Bowman Gilfillan Africa Group, Employment Law Article.

23. Marshall, C. \& Rossman, G.B. (2010). Designing qualitative research. $5^{\text {th }}$ edition. California: Sage Publications.

24. McInnis, K.J., Meyer, J.P. \& Feldman, S. (2009). Psychological contracts and their implications for commitment: A feature-based approach, Journal of Vocational Behavior, 74, pp. 165-180.

25. Mokoditoa, J.M. (2011). Academic staff recruitment and retention strategies at the University of Limpopo. MPA dissertation, Turfloop Graduate School of Leadership, University of Limpopo, Polokwane, South Africa.

26. Saurin, R. (2012). Workplace futures: A case study of an adaptive scenarios approach to establish strategies for tomorrow's workplace, PhD thesis, College of Engineering and Built Environment, School of Spatial Planning, Dublin Institute of Technology.

27. South Africa. (1999). Employment Equity Act of 1998. Pretoria: Government Printers.

28. Taylor, M.S. \& Collins, C.J. (2000). Organizational recruitment: enhancing the intersection of theory and practice. In Cooper, C.L. \& Locke, E.A. (eds.), Industrial and organizational psychology: Linking theory and practice. Basil Blackwell, Oxford, pp. 304-334.

29. Thomas, G. (2011). A typology for the case study in social science following a review of definition, discourse and structure, Qualitative Inquiry, 17 (6), pp. 511-521.

30. Thompson, C. (2003). The changing nature of employment. 24 ILJ 1793 at 1794; 1815.

31. Thorsteinson, T.J. (2003). Job attitudes of part-time vs. full-time workers: A meta-analytic review, Journal of Occupational and Organizational Psychology, 76, pp. 151-177.

32. Valverde, M., Tregaskis, O. \& Brewster, C. (2000). Labor flexibility and firm performance, International Advances in Economic Research, 6, pp. 649-661.

33. van Wyk, J., van Heerden, A. \& Feldman, B. (2015). Is an employee on a fixed term contract entitled to a $13^{\text {th }}$ cheque? Workmans Attorneys Newsletter, $4^{\text {th }}$ September. 
34. Van Zyl, C. \& Rudd, C. (2006). South African Labor Law Reports (SALLR). $22^{\text {nd }}$ Annual Seminar, Van Zyl, Rudd \& Associates (Pty) Ltd, Port Elizabeth.

35. Venter, R. (2003). Labor Relations in South Africa. $2^{\text {nd }}$ edition. Oxford: Oxford University Press.

36. Voudouris, I. (2004). The use of flexible employment arrangements: some new evidence from Greek firms, International Journal of Human Resource Management, 15 (1), pp. 131-146.

37. Wandera, H.T. (2011). The effects of short term employment contract on an organization: A case of Kenya forest service, International Journal of Humanities and Social Science, 1 (21), pp. 184-204.

38. Wiens-Tuers, B.A. \& Hill, E.T. (2002). Do they bother? Employer training of temporary workers, Review of Social Economy, 60, pp. 543-566.

39. Yin, R.K. (2014). Case study research: Design and methods. $5^{\text {th }}$ edition. California: Sage Publications.

40. Zijl, M., van den Berg, G.J. \& Heyma, A. (2004). Stepping stones for the unemployed: The effect of short term jobs on the duration until regular work (Discussion Paper $\mathrm{N}^{\mathbf{0}} 1241$ ). Bonn: Institute for the Study of Labor. 